une revue Gallia

Rhône-Alpes | 2007

\title{
Ternay (Rhône)
}

La Sarrasinière

\section{Frédérique Blaizot}

\section{(2) OpenEdition \\ 1 Journals}

Édition électronique

URL : http://journals.openedition.org/adlfi/6836

ISSN : 2114-0502

Éditeur

Ministère de la Culture

Référence électronique

Frédérique Blaizot, «Ternay (Rhône) », ADLFI. Archéologie de la France - Informations [En ligne], RhôneAlpes, mis en ligne le 01 mars 2007, consulté le 14 novembre 2019. URL : http:// journals.openedition.org/adlfi/6836

Ce document a été généré automatiquement le 14 novembre 2019.

(c) Ministère de la Culture et de la Communication, CNRS 


\title{
Ternay (Rhône)
}

\author{
La Sarrasinière
}

\section{Frédérique Blaizot}

Identifiant de l'opération archéologique : 229410

Date de l'opération : 2007 (SP)

1 L'opération archéologique porte sur un décapage de $464,9 \mathrm{~m}^{2}$ sur la pente d'un coteau surplombant le Rhône. Les premières traces d'une occupation sont illustrées par deux fosses. L'une, de forme rectangulaire, renferme des galets et des terres cuites architecturales, l'autre, circulaire, contient du mobilier de la période augustéenne mêlé à des galets et des éléments architecturaux (tuiles, pilettes d'hypocauste, antéfixe). Ces deux fosses s'inscrivent dans deux couches; la première correspond à un colluvionnement aéré de galets qui livre du mobilier également attribuable à l'époque augustéenne. Elle est surmontée d'une couche de limon résultant de ruissellements dans laquelle a été recueilli un fragment de corniche moulurée en marbre. L'ensemble, colluvions, ruissellements et fosses sont donc contemporains, tandis que le mobilier témoigne d'un habitat de qualité manifestement établi plus haut à proximité de la zone décapée.

2 La seconde occupation se rapporte à un petit ensemble funéraire daté au plus tôt de la fin du VII $s$. et du VIII ${ }^{e}$ s. On ne connaît pas son étendue au nord-ouest, cette partie ayant été détruite par deux tranchées, l'une liée à la construction du talus de la voie ferrée et l'autre lors de l'installation, en 2004, d'un tuyau d'évacuation des eaux usées pour le lotissement. Nous avons exhumé sept tombes totalisant un nombre minimum de quatorze squelettes, trois d'entre elles ayant été utilisées pour des inhumations successives. Les tombes recoupent les mêmes couches que les fosses augustéennes. Six sont illustrées par des coffrages composites (blocs, pilettes et tuiles récupérées de l'époque augustéenne, dalles de schiste et bois) trapézoïdaux ou hexagonaux, la typologie de la septième, très érodée, n'a pas pu être déterminée (coffrage de bois ou tombe en fosse à couverture de bois). Des effets de contraintes latérales qui se sont produits à distance des parois internes du coffrage ont été relevés sur trois squelettes ; 
ils indiquent que le corps reposait dans un contenant de bois placé ou pratiqué à l'intérieur du coffrage de pierre. Dans les trois sépultures collectives, les os des précédents occupants ont fait l'objet de rangements après avoir été sélectionnés. Chacune d'entre elles illustre un mode de gestion différent des os en situation secondaire (construction d'une «case » dans le coffrage initial, ou rangement des os entre les parois internes du coffrage de pierre et les parois externe du coffrage de bois de la dernière inhumation, et enfin regroupement des os dans le comblement du coffrage). La composition par âge de la population archéologique montre un important déficit sur les classes d'âge avant dix ans. Toutefois, les limites de l'investigation archéologique et les destructions opérées par des tranchées récentes ne permettent pas d'interpréter ce résultat comme un choix culturel, la population fouillée pouvant ainsi ne pas correspondre à la population inhumée. L'ensemble des caractéristiques de cette zone funéraire semble toutefois indiquer qu'il s'agit probablement d'un lieu d'inhumation dévolu à une microsociété sans doute à caractère familial, lié à un petit établissement et utilisé sur une assez courte durée ne dépassant sans doute pas un siècle, comme il en existe de nombreux exemples dans le finage des habitats de l'Antiquité à la fin du haut Moyen Âge. L'état des connaissances sur le secteur reste malheureusement insuffisant pour localiser l'habitat, voire pour mettre cet ensemble funéraire en relation avec d'autres lieux sépulcraux ayant éventuellement pu coexister avec celui-ci.

\section{INDEX}

Index chronologique : Empire romain, haut Moyen Âge, Haut-Empire, Ier siècle apr. J.-C., VIIe siècle apr. J.-C., VIIIe siècle apr. J.-C.

operation Sauvetage programmé (SP)

Index géographique : Rhône-Alpes, Rhône (69), Ternay

\section{AUTEURS}

FRÉDÉRIQUE BLAIZOT

INRAP 